NASA Technical Memorandum 105549

$$
\begin{aligned}
& \text { NASA-TM-105549 } \\
& \text { CONF-920801--31 }
\end{aligned}
$$

\title{
Comparison of GLIMPS and HFAST Stirling Engine Code Predictions With Experimental Data
}

Steven M. Geng and Roy C. Tew

Lewis Research Center

Cleveland, Ohio

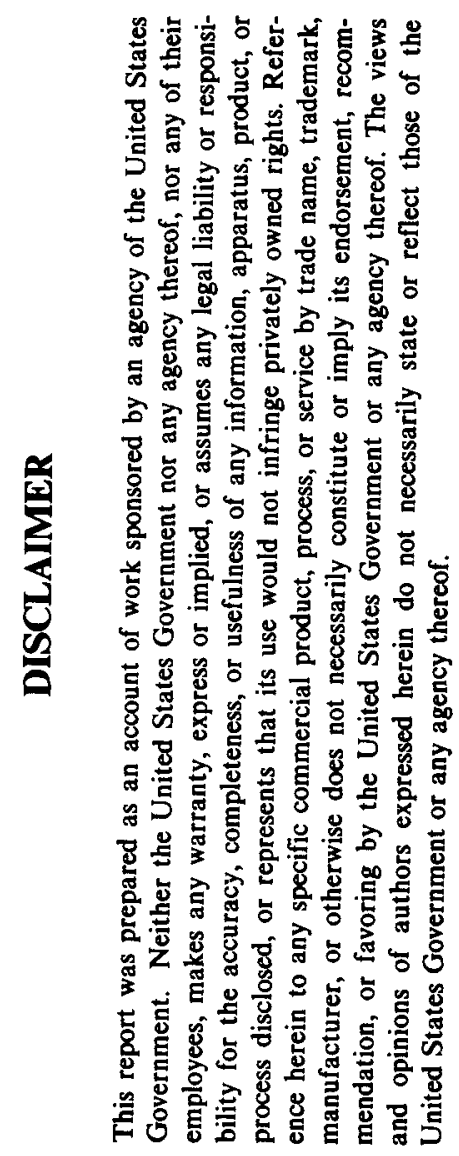

Prepared for the

27th Intersociety Energy Conversion Engineering Conference cosponsored by the SAE, ACS, AIAA, ASME, IEEE, AlChE, and ANS San Diego, California, Augast 3-7, 1992 


\section{DISCLAIMER}

This report was prepared as an account of work sponsored by an agency of the United States Government. Neither the United States Government nor any agency Thereof, nor any of their employees, makes any warranty, express or implied, or assumes any legal liability or responsibility for the accuracy, completeness, or usefulness of any information, apparatus, product, or process disclosed, or represents that its use would not infringe privately owned rights. Reference herein to any specific commercial product, process, or service by trade name, trademark, manufacturer, or otherwise does not necessarily constitute or imply its endorsement, recommendation, or favoring by the United States Government or any agency thereof. The views and opinions of authors expressed herein do not necessarily state or reflect those of the United States Government or any agency thereof. 


\section{DISCLAIMER}

Portions of this document may be illegible in electronic image products. Images are produced from the best available original document. 
Steven M. Geng and Roy C. Tew

National Aeronautics and Space Administration

Lewis Research Center

Cleveland, Ohio 44135

\section{ABSTRACT}

Predictions from GLIMPS and HFAST design codes are compared with experimental data for the RE-1000 and SPRE free-piston Stirling engines. Engine performance and available power loss predictions are compared. Differences exist between GLIMPS and HFAST loss predictions. Both codes require engine-specific calibration to bring predictions and experimental data into agreement.

\section{INTRODUCTION}

GLIMPS and HFAST are the two primary Stirling design codes being used by NASA and its contractors. Although the two codes can be calibrated to predict similar gross

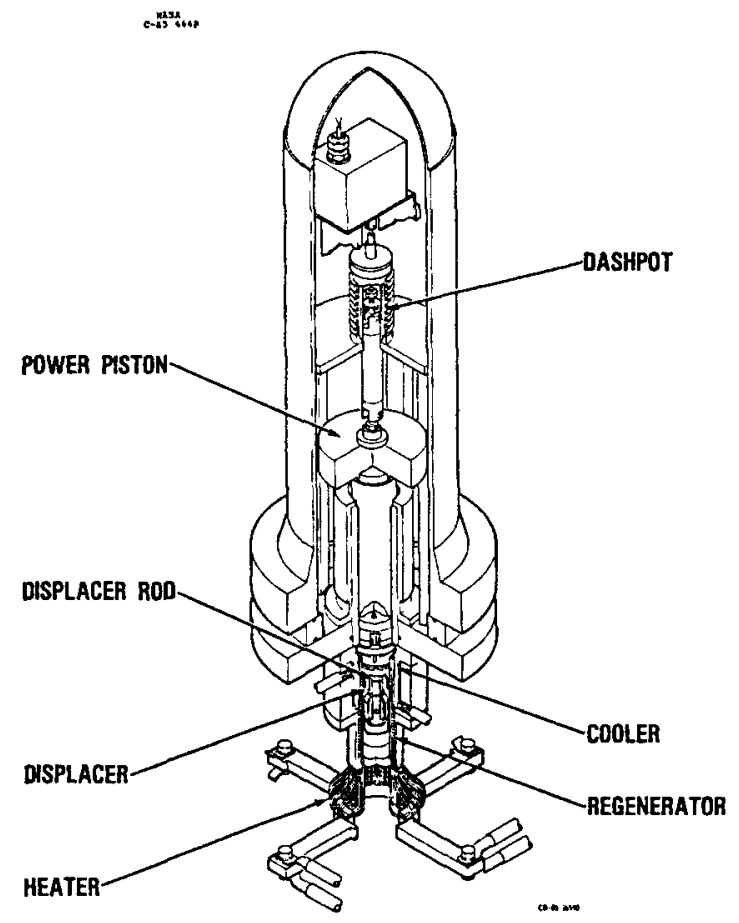

Figure 1 - Cutaway View of RE-1000 Free-Piston, Stirling Engine performance for several engines, differences exist in their loss predictions. This paper focuses on 1) the calibration requirements of each code, 2) the predicted engine performance and available power losses, and 3) comparisons of the code predictions with experimental data.

The RE-1000 and SPRE Stirling engines were modeled with both GLIMPS and HFAST. The RE- 1000 is a $1-\mathrm{kW}$ free-piston Stirling engine designed and built by Sunpower Inc., of Athens, OH. It was obtained in 1979 for testing as part of the NASA Stirling engine technology program at Lewis. The RE-1000 is an electrically heated single-cylinder engine with a dashpot load ${ }^{1}$; a cutaway view is shown in Fig. 1. The SPRE (Space Power Research Engine) is a $12.5-\mathrm{kW}$ free-piston Stirling engine designed and built by Mechanical Technology, Inc., of Latham, NY, under contract with NASA. The SPRE is a single-cylinder engine with a linear alternator load $^{2}$; a cutaway view is shown in Fig. 2. The design operating conditions of each engine are given in Table 1 .

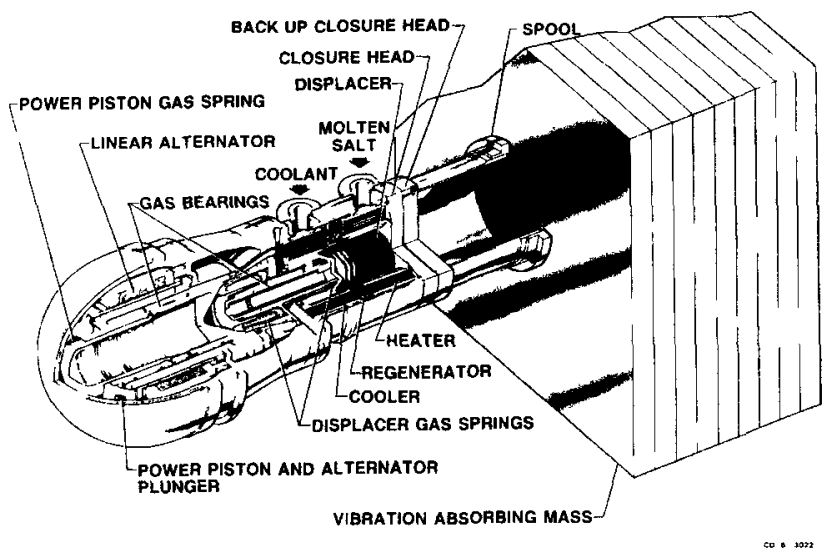

Figure 2 - Cutaway View of SPRE Free-Piston, Stirling Engine

GLIMPS and HFAST were each calibrated using both RE-1000 and SPRE test data. Performance predictions are shown with and without the use of the calibration parameters for each engine. The power and efficiency terms used are consistent with the definitions proposed by the ASME Stirling engine technical committee ${ }^{3}$. 
Table 1. RE-1000 and SPRE Design Operating Conditions

\begin{tabular}{|c|c|c|c|}
\hline Parameter & & $\begin{array}{c}\text { RE-1000 } \\
\text { Rdg \#1010 }\end{array}$ & $\begin{array}{c}\text { SPRE } \\
\text { Rdg \#1215 }\end{array}$ \\
\hline Working Fluid & & Helium & Helium \\
\hline Pressure & $\mathrm{MPa}$ & 7.0 & 15.0 \\
\hline Ave. Heater Temp & ${ }^{\circ} \mathrm{C}$ & 600 & 341 \\
\hline Ave. Cooler Temp & ${ }^{\circ} \mathrm{C}$ & 57 & 33 \\
\hline Frequency & $\mathrm{Hz}$ & 30.1 & 102.3 \\
\hline Displacer Phase & $\circ$ & 57.5 & 76.4 \\
\hline Piston Stroke & $\mathrm{cm}$ & 2.60 & 2.02 \\
\hline Displacer Stroke & $\mathrm{cm}$ & 2.34 & 2.13 \\
\hline
\end{tabular}

\section{GLIMPS AND HFAST STIRLING SIMULATIONS}

GLIMPS is a constrained mode simulation that uses a globally implicit technique to solve a system of algebraic equations simultaneously. The algebraic equations are finite difference representations of the governing differential equations. GLIMPS is a one-dimensional model comprised of up to 7 components relating to the working space of a Stirling cycle machine. Each component is divided into a number of computational-cells. The computational domain is broken into discrete time nodes as well. The user specifies the number of computational-cells and time nodes used in the model. GLIMPS, developed by Gedeon Associates, recently has been upgraded to version $4.0^{4,5}$.

HFAST is a constrained mode simulation that assumes the variables are harmonic functions of time. The solution is found by solving a system of nonlinear, algebraic equations which are created by substituting harmonic functions in the governing differential equations. HFAST is a one-dimensional model comprised of a variable number of components relating to the working space of a Stirling cycle machine. Each component is divided into a number of control-volumes. The user specifies the number of components and control-volumes used in the model. HFAST, written by Mechanical Technology, Inc., has recently been upgraded to version $2.0^{6}$.

\section{GLIMPS AND HFAST ENGINE MODELS}

GLIMPS RE-1000 MODEL - Two computational-cells were used each in the cooler, regenerator manifolds, and heater. Four computational-cells were used in the regenerator. Twelve time nodes per cycle were used for all predictions. GLIMPS does not allow all connecting-ducts to be modeled directly. The expansion-space-to-heater connecting-duct volume was lumped with the expansion-space. The compression-space-to-cooler connecting-duct volume was lumped with the compression-space.

Portions of the RE- 1000 regenerator manifolds are not in the working-space gas flow stream. These portions were lumped with the expansion and compression-space volumes.

The heater and cooler temperatures were assumed constant over their length. This assumption was made since no experimental data were taken to clearly define the wall temperature gradient. The actual RE-1000 heater and cooler temperatures were not uniform.
HFAST RE-1000 MODEL - Two control-volumes were used each in the cooler, regenerator manifolds, and heater. Four control-volumes were used in the regenerator. One control-volume was used for the expansion-space-to-heater connecting-duct while two control-volumes were used for the compression-space-to-cooler connecting-duct; note that, unlike GLIMPS, these connecting-ducts were not lumped with the expansion and compression-spaces.

To be consistent with GLIMPS, the portions of the regenerator manifold volumes not in the working-space gas flow stream were lumped with the expansion and compressionspace volumes.

The temperatures of the heater and cooler were assumed constant over their length. This assumption was made for the reason explained for the GLIMPS model.

GLIMPS SPRE MODEL - Four computational-cells were used each in the cooler, regenerator, and heater. Two computational-cells were used in each regenerator manifold. No connecting-duct exists between the expansion-space and heater. The compression-space-to-cooler connecting-duct volume and surface area were lumped in with the compressionspace.

HFAST SPRE MODEL - Four control-volumes were used each in the cooler, regenerator, and heater. Only one controlvolume could be used for each regenerator manifold. Two could not be used since HFAST limits the total number of control-volumes in the model. The one control-volume manifold models should not cause difficulties when comparing the HFAST and GLIMPS predictions since the SPRE manifolds are small. Two control-volumes were used for the compression-space-to-cooler connecting-duct which is extremely large; note that, unlike GLIMPS, this connectingduct volume was not lumped with the compression-space.

\section{CODE CALIBRATION}

Calibration parameters are defined as the set of multiplication factors and coefficients required to adjust predicted pressure drops, heat transfer, and gas flow rates. The term factor refers to the subset of dimensionless calibration parameters while the term coefficient refers to the subset of calibration parameters that have physical properties. The parameters used to calibrate GLIMPS and HFAST are shown in Table 2. Note that no leakage coefficients were used to calibrate GLIMPS. A leakage model has been added to the main simulation of GLIMPS 4.0. However, it was not operational in the beta version of the code that was used for this paper. Leakage calculations were made in the GLIMPS postprocessor. These leakages could not be used to calibrate GLIMPS since they have no affect on the engine pressure waves calculated in the main simulation.

A performance map was generated for each code by varying each calibration parameter individually. The maps were used as a guide to adjust the parameters to bring the code predictions into better agreement with the test data.

The performance parameters of interest for the RE-1000 calibration included: 1) engine power, 2) gross engine thermal efficiency, 3) compression-space pressure amplitude, 4) compression-space pressure phase angle, 5) power input to engine heater, and 6) power rejected to the coolant. 
Table 2. GLIMPS and HFAST Calibration Parameters

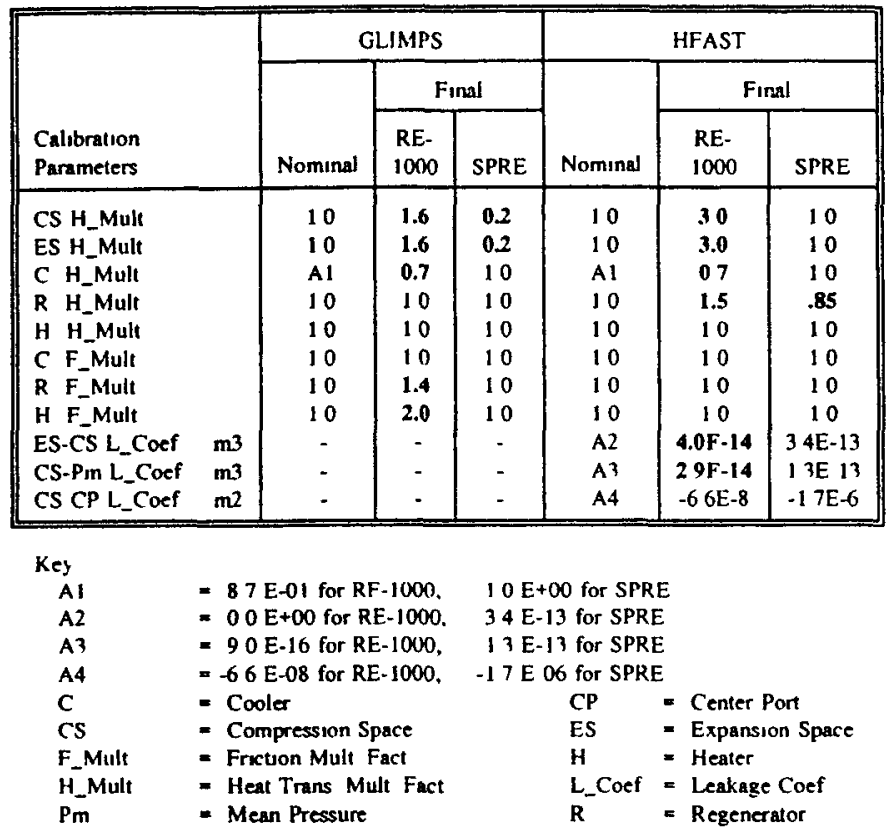

The performance parameters of interest for the SPRE calibration included: 1) piston PV (Pressure-Volume) power, 2) piston PV efficiency, 3) compression-space pressure amplitude, 4) compression-space pressure phase angle, 5) power input to engine heater, and 6) power rejected to the coolant.

For the RE-1000, the engine power and gross engine thermal efficiency were the most accurate of the experimental power and efficiency measurements. For the SPRE, engine power and thus gross engine thermal efficiency measurements were not possible due to the instrumentation. The linear alternator is an integral part of the SPRE power piston. The engine power is defined by $\mathrm{ASME}^{3}$ as the power delivered to the output convertor by the engine (i.e. engine power = indicated power - piston and displacer losses). The linear alternator is the output convertor for the SPRE. The only power and efficiency measurements that could be compared with the code predictions on an equivalent basis were piston PV power and efficiency.

GLIMPS and HFAST were calibrated at the design operating conditions of each engine (RE-1000 Rdg \#1010 and SPRE Rdg \#1215). The calibration parameters were adjusted until all or most of the performance parameters of interest were within the error bands of the test data. No attempt was made to further calibrate within the error bands or over a range of operating conditions. The nominal and final calibration parameters are shown in Table 2.

\section{COMPARISON OF ENGINE THERMODYNAMICS}

GLIMPS and HFAST predictions are compared in Tables 3 and 4 . The experimental data are shown for each engine at its design operating conditions. Uncalibrated and calibrated predictions are shown for each code.

RE-1000 COMPARISONS - Table 3 shows the code predictions for the RE-1000 at its design operating conditions. The engine power and gross engine thermal efficiency were two of the six performance parameters for which the codes were calibrated. Note that HFAST does not directly calculate engine power. To be consistent with GLIMPS, the piston gas spring hysteresis loss (not shown separately in the Tables) was subtracted from the piston PV power to obtain the HFAST engine power.

Table 3. RE-1000 Performance at Design Operating Conditions

\begin{tabular}{|c|c|c|c|c|c|c|}
\hline \multirow[b]{2}{*}{ Parameter } & & \multirow{2}{*}{$\begin{array}{c}\text { Test } \\
\text { Dara } \\
\# 1010\end{array}$} & \multicolumn{2}{|c|}{ UNCALIBRATED } & \multicolumn{2}{|c|}{ CALIBRATED } \\
\hline & & & GLIMPS & HFAST & GLIMPS & HFAST \\
\hline Indicated Powet & w & & 1201 & 1317 & 976 & 1212 \\
\hline Indicated Engine Efficiency & $\%$ & & 31.3 & 311 & 269 & 324 \\
\hline Engine Power & w & 866 & 1071 & 1225 & 885 & 891 \\
\hline Gross Engine Thermal Eff & $\%$ & 238 & 269 & 289 & 244 & 238 \\
\hline Nel Displacer PV & W & & 111 & 34 & 34 & 42 \\
\hline CS Pressure Amplirude & $\mathrm{MPa}$ & 115 & 116 & 114 & 113 & 114 \\
\hline CS Pressure Phase Angle & - & 157 & 167 & 199 & 148 & -143 \\
\hline Parasitic Heat Loss & $w$ & & 308 & 301 & 301 & 234 \\
\hline Parasitic Power Loss & w & & 60 & 58 & 57 & 279 \\
\hline Heat Inpu & w & 3643 & 3876 & 4238 & 3623 & 3737 \\
\hline Heat Rejected & $w$ & 2736 & 2694 & 2947 & 2704 & 2773 \\
\hline Carnol Efficiencs & $\%$ & 62.2 & 62.2 & 62.2 & 62.2 & 622 \\
\hline Avallabie Power & $\mathbf{w}$ & 2266 & 2386 & 2636 & 2253 & 2324 \\
\hline Lost Avalable Power (LAP) & $w$ & & 1185 & 1319 & $127^{\circ}$ & 112 \\
\hline $\begin{array}{l}\text { liemized LAP } \\
\text { Yiscous Dissipation }\end{array}$ & $\mathbf{w}$ & & 69 & 105 & 98 & 93 \\
\hline Gas to-Wall Heat Transfer & & & & & & \\
\hline In Phase With $\Delta T$ & $\mathbf{w}$ & & 627 & 599 & 690 & 504 \\
\hline Leading AT & w & & & 70 & - & 74 \\
\hline Gas Conduction & $w$ & & 99 & 10 & 96 & 10 \\
\hline Mixing Loss & $w$ & & - & 127 & - & 102 \\
\hline Parasitc Heat Loss & $w$ & & 192 & 187 & 187 & 145 \\
\hline Total & w & & 987 & 1098 & 1071 & 928 \\
\hline$\sigma_{0}$ Ermr & $\mathscr{*}$ & & -167 & -168 & -161 & -165 \\
\hline
\end{tabular}

Ideally, the net displacer PV power should be zero for all predictions. A non-zero value indicates a mismatch between the predicted thermodynamics and the assumed dynamics (i.e. a positive net displacer PV indicates that more power is going into the displacer than is consumed by displacer losses).

The parasitic heat loss prediction includes the following: 1) wall conduction, 2) displacer shell conduction, 3) displacer internal gas conduction, 4) displacer shuttle loss, ard 5) displacer appendix gap loss. The parasitic power loss prediction includes the following: 1) piston center-port leakage, 2) piston seal leakage, 3) piston gas-spring hysteresis, 4) displacer center-port leakage, 5) displacer gas-spring seal leakage, and 6) displacer gas-spring hysteresis. The heat input and heat rejected predictions include the effects of the parasitic heat losses.

Available power was calculated by multiplying the heat input by the Carnot efficiency. Lost available power (LAP) was then calculated by subtracting the indicated power from the available power. HFAST predicted higher available power for both uncalibrated and calibrated comparisons. HFAST predicted higher LAP for the uncalibrated comparison but lower LAP for the calibrated comparison.

Thermodynamic 2nd law LAP analysis wav ${ }^{\prime}$ ', incorporated in GLIMPS and HFAST to permut separation of irreversibilities due to different loss mechanisms. The resulting irreversibilities or available power losses, itemized in Table 3, are: 1) viscous dissipation loss, 2) gas-to-wall heat transfer in phase with the temperature difference between the mean gas and wall temperatures, 3) gas-to-wall heat transfer leading the temperature difference, 4) gas axial conduction, 5) gas mixing loss, and 6) parasitic heat loss.

In general, heat transfer is out of phase with the meangas-to-wall temperature difference in Stirling cycle machines. 
The gas-to-wall heat transfer in phase with temperature difference shown in Table 3 (and 4) was calculated based on steady-flow heat transfer correlations which do not account for this phase shift. HFAST calculates an additional heat transfer which leads temperature difference based on a correlation developed by Lee ${ }^{7}$. This additional heat transfer is intended to correct the steady-flow heat transfer for phase shift. In contrast, GLIMPS does not attempt to correct the steady-flow heat transfer for phase shift.

GLIMPS does not calculate gas mixing losses at the component interfaces. GLIMPS assumes a continuous temperature distribution between computational-cells (unlike HFAST). According to Gedeon, GLIMPS accounts for the mixing losses under enhanced gas axial conduction.

Available power loss due to parasitic heat loss was computed by multiplying total parasitic heat loss by the Carnot efficiency. In an ideal engine, the parasitic heat loss would contribute to indicated power. Indicated power would be larger by the parasitic heat loss multiplied by the Carnot efficiency.

In the uncalibrated comparisons between GLIMPS and HFAST, GLIMPS predicted lower viscous dissipation and gasto-wall heat transfer, but higher gas conduction loss. The parasitic heat losses were about the same.

In the calibrated comparisons, GLIMPS predicted higher gas-to-wall heat transfer, gas conduction, and parasitic heat losses. Although not shown in the tables, higher GLIMPS gasto-wall heat transfer losses are largely due to the larger cylinder heat transfer predicted by GLIMPS. The viscous dissipation loss was roughly the same for the two codes.

The itemized available power losses were summed and checked against the previous LAP calculation. The percent error in the summation of these itemized losses ranged from $-16.1 \%$ to $-16.8 \%$. Thus, it appears that some itemized losses are being underestimated or completely overlooked.

SPRE COMPARISONS - Table 4 shows the code predictions for the SPRE at its design operating conditions. Note that the accuracy of the experimental heater and coolertube temperatures is questionable for the SPRE. The predicted performance of the SPRE is extremely sensitive to temperature ratio. Any error in heater or cooler temperature has a large effect on calculated performance.

The piston PV power and efficiency were two of the performance parameters for which the codes were calibrated. GLIMPS predicted a significantly lower piston PV power and efficiency than HFAST in the uncalibrated comparison. The GLIMPS piston PV power and efficiency were only slightly higher in the calibrated comparison.

The total parasitic heat and power losses for the SPRE include the same losses as for the RE-1000. The SPRE has an additional displacer gas spring and several more leakage paths than the RE-1000. These additional losses have been taken into account. HFAST predicts significantly larger parasitic heat and power losses for both the uncalibrated and calibrated comparisons.

LAP for the SPRE predictions were re-calculated by summing the individual losses. The available power losses for the SPRE are itemized in Table 4 . The percent error in the LAP calculations ranged from $-0.6 \%$ to $-17.3 \%$.
Table 4. SPRE Performance at Design Operating Conditions

\begin{tabular}{|c|c|c|c|c|c|c|}
\hline \multirow[b]{2}{*}{ Parameter } & & \multirow{2}{*}{$\begin{array}{c}\text { Test } \\
\text { Data } \\
1219\end{array}$} & \multicolumn{2}{|c|}{ UNCALIBRA TED } & \multicolumn{2}{|c|}{ CALIBRATED } \\
\hline & & & GLIMPS & HFAST & GLIMPS & HFAST \\
\hline Indicated Power & $\mathbf{w}$ & & 12310 & 17359 & 15740 & 17012 \\
\hline Indicated Engine Efficiency & $\%$ & & 198 & 287 & 249 & 271 \\
\hline Piston PV Power & w & 12800 & 9702 & 12839 & 13021 & 12532 \\
\hline Piston PV Efficiency & * & 20.3 & 156 & 21.2 & 206 & 200 \\
\hline Engine Power & w & & 9015 & 12152 & 12334 & 11845 \\
\hline Net Displacer PV & u & & -84 & 411 & -56 & 414 \\
\hline CS Pressure Amplitude & MPa & 173 & 162 & 165 & 164 & 163 \\
\hline CS Pressure Pluase Angle & - & 80 & 74 & 84 & 96 & 83 \\
\hline Parasitic Heat Loss & $\mathbf{w}$ & & 941 & 2861 & 954 & 2953 \\
\hline Parnsitic Power Loss & $\mathbf{w}$ & & 3381 & 4144 & 3468 & 4085 \\
\hline Heat Input & $\mathbf{w}$ & 67120 & 62167 & 60584 & 63130 & 62798 \\
\hline Heat Reyected & $w$ & 52730 & 53239 & 46177 & 50847 & 48681 \\
\hline Carnot Efficiency & $\boldsymbol{\sigma}$ & 501 & 501 & 501 & 501 & 501 \\
\hline Alailable Poner & w & 31623 & 31146 & 30353 & 31628 & 31462 \\
\hline Lost Avallable Power (LAP) & w & & 18836 & 12994 & 15838 & 14450 \\
\hline \multicolumn{7}{|l|}{ Itemized LAP } \\
\hline Viscous Dissipation & $\mathbf{w}$ & & 2210 & 3115 & 2196 & 3103 \\
\hline \multicolumn{7}{|l|}{ Gas to-Wall Heat Transfer } \\
\hline In Phase With $\Delta \mathrm{T}$ & $\mathbf{w}$ & & 11652 & 6064 & 8769 & 6655 \\
\hline Leading $\Delta T$ & w & & & 712 & & 704 \\
\hline Gas Conduction & w & & 1698 & 52 & 1704 & 53 \\
\hline Mixıng Loss & w & & & 1534 & & 1687 \\
\hline Parasitic Heat Loss & $\mathbf{w}$ & & 471 & 1433 & 478 & 1479 \\
\hline Total & w & & 16031 & 12910 & 13147 & 13681 \\
\hline \& Error & 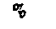 & & 149 & 06 & 173 & 53 \\
\hline
\end{tabular}

In both uncalibrated and calibrated comparisons, GLIMPS predicted lower viscous dissipation and parasitic heat losses but much higher gas-to-wall heat transfer and gas conduction losses. Again, the high GLIMPS gas-to-wall heat transfer losses are due to much higher cylinder heat transfer.

\section{COMPARISON OF POWER AND EFFICIENCY}

Comparisons of predicted and measured data are shown as a function of piston amplitude in Figs. 3 through 10. Error bars have been placed on the experimental data. The error bars indicate the measurement error associated with each reading.

Figure 3 shows the uncalibrated engine power predictions for the RE-1000. Both codes over-predicted the power over the range of piston amplitudes modeled. GLIMPS and HFAST predicted a drop-off in the rate of increase in power at the higher amplitudes. The test data showed a linear increase in engine power with piston amplitude. The reason for this dropoff is not clear.

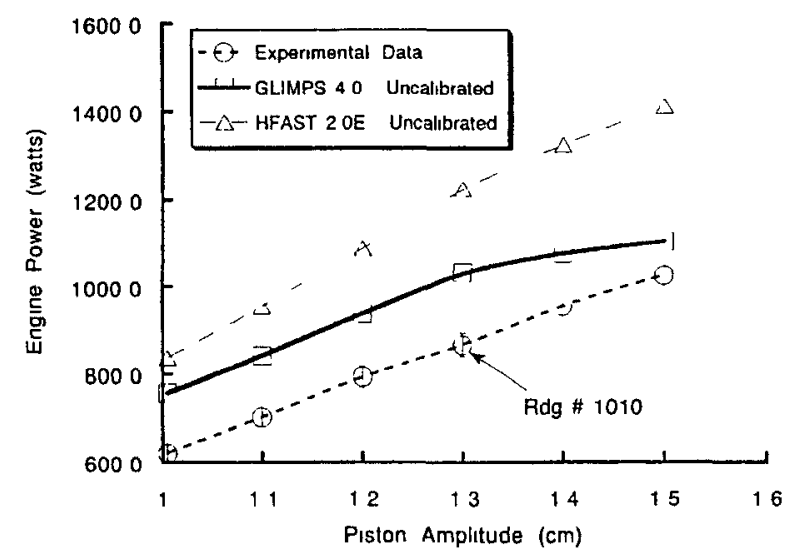

Figure 3 - RE-1000 Engine Power vs Piston Amplitude (Uncalibrated Predictions) 
Figure 4 shows the uncalibrated gross engine thermal efficiency predictions for the RE-1000. Both codes overpredicted the efficiency over the entire range of piston amplitudes modeled. GLIMPS predicted a decrease in efficiency with increasing piston amplitude while HFAST predicted an efficiency curve with a trend similar to the test data. This difference in behavior indicates that at least one loss predicted by GLIMPS is overly sensitive to piston stroke.

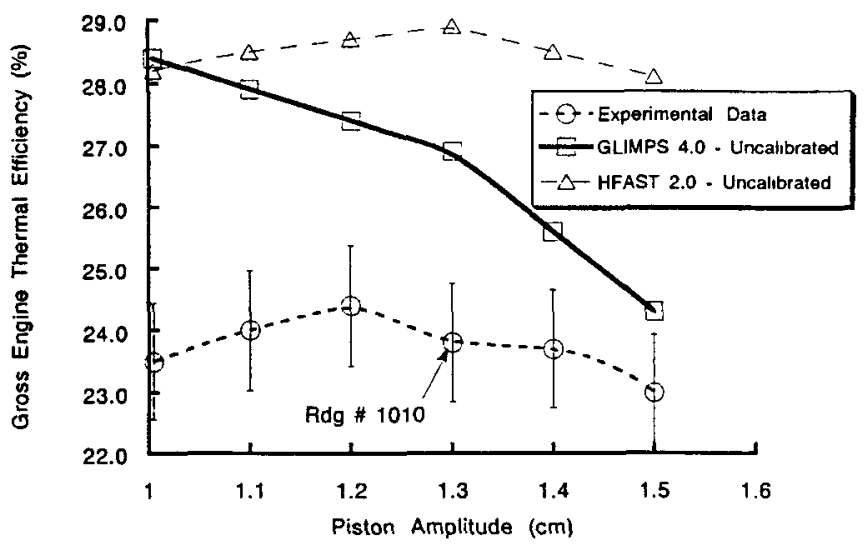

Figure 4 - RE-1000 Gross Engine Thermal Efficiency vs Piston Amplitude (Uncalibrated Predictions)

Figure 5 shows the calibrated engine power predictions for the RE-1000. Agreement with the data was much improved at design and lower piston amplitudes; at higher amplitudes, the drop-off in the rate of predicted power increase is still apparent.

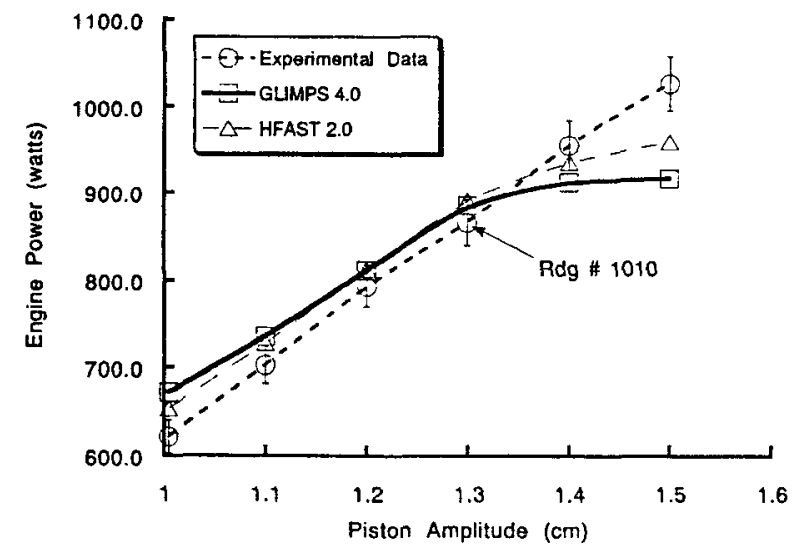

Figure 5 - RE-1000 Engine Power vs Piston Amplitude (Calibrated Predictions)

Figure 6 shows the calibrated gross engine thermal efficiency predictions for the RE-1000. Both codes overpredicted efficiency at low amplitudes and under-predicted efficiency at high amplitudes. Note that in the uncalibrated predictions shown in Fig. 4, the trend of the HFAST efficiency curve matched the trend of the data. Each calibration parameter was varied to determine which one shifted the trend. All parameters caused the efficiency curve to shift. These results indicate that the codes are incorrectly predicting a loss or losses for which no calibration parameter currently exists.

Figure 7 shows the uncalibrated piston PV power predictions for the SPRE. GLIMPS significantly underpredicted power over the range of piston amplitudes modeled.
The HFAST predictions were within the experimental error bars over the entire range. Note that evolutionary changes to HFAST have been guided by SPRE data, and an earlier version of HFAST was used to design this engine.

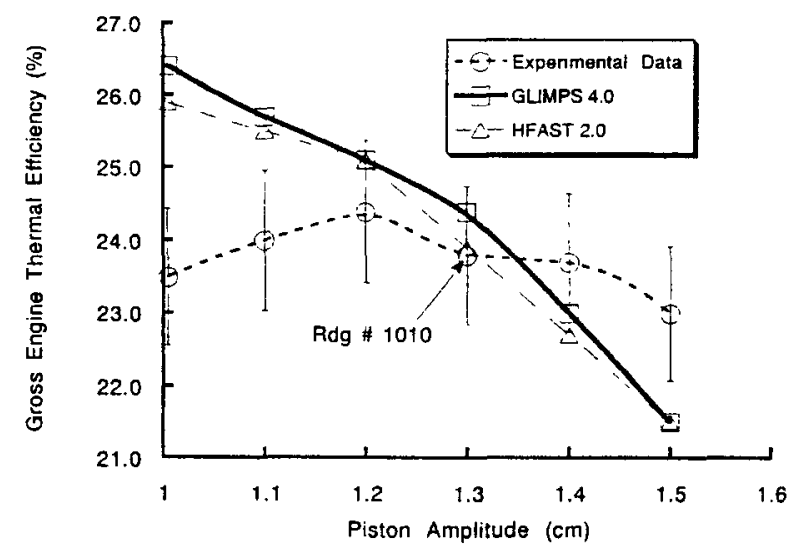

Figure 6 - RE-1000 Gross Engine Thermal Efficiency vs Piston Amplitude (Calibrated Predictions)

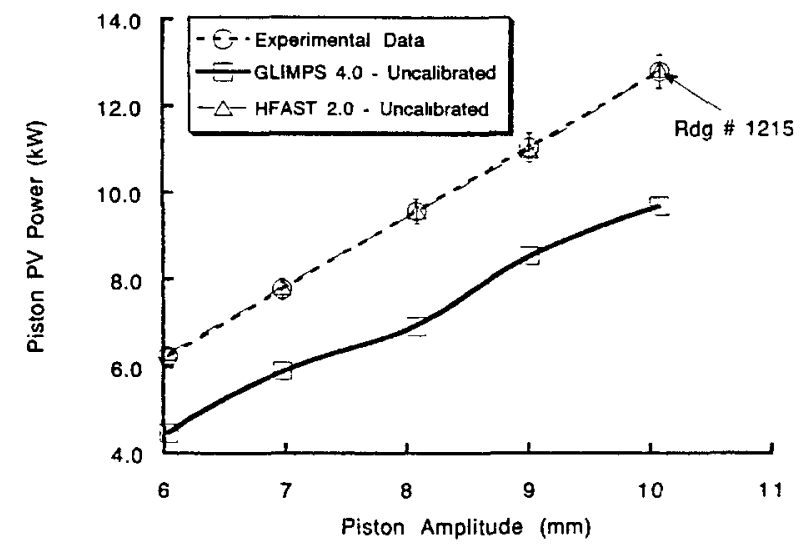

Figure 7 - SPRE Piston PV Power vs Piston Amplitude (Uncalibrated Predictions)

Figure 8 shows the uncalibrated piston PV efficiency predictions for the SPRE. GLIMPS significantly underpredicted efficiency while HFAST slightly over-predicted efficiency. The waviness in the GLIMPS efficiency curve may be due to numerical error.

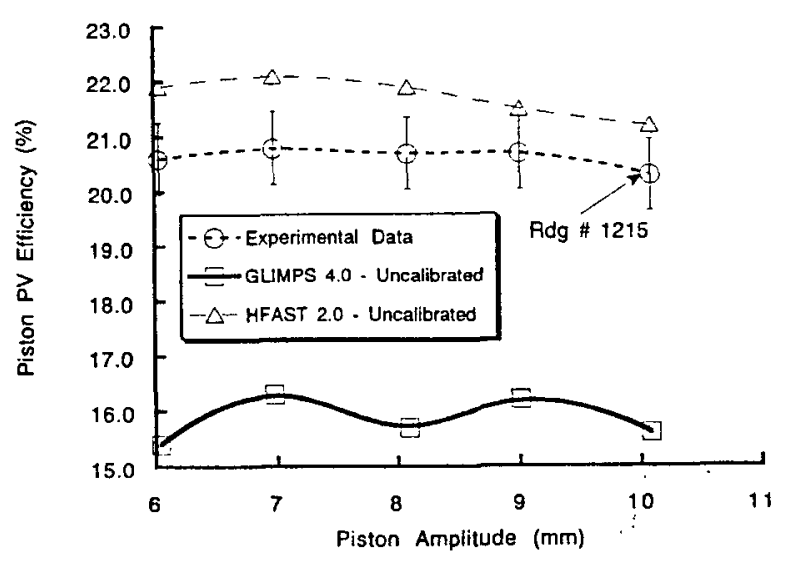

Figure 8 - SPRE Piston PV Efficiency vs Piston Amplitude (Uncalibrated Predictions) 
Figure 9 shows the calibrated piston $P V$ power predictions for the SPRE. GLIMPS under-predicted power at the low piston amplitudes. The agreement between the GLIMPS predictions and the experimental data was good at the higher piston amplitudes. The HFAST predictions were within the experimental error bars over the range of piston amplitudes modeled.

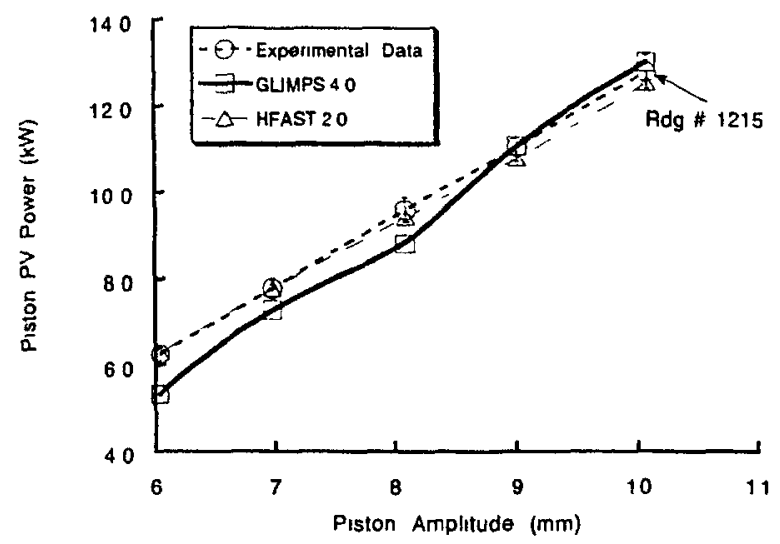

Figure 9 - SPRE Piston PV Power vs Piston Amplitude (Calibrated Predictions)

Figure 10 shows the calibrated piston PV efficiency predictions for the SPRE. GLIMPS significantly underpredicted efficiency at the low piston amplitudes. The HFAST predictions were within the experimental error bars over most of the range of piston amplitudes modeled. Although the calibration brought both codes into agreement with the data at the design piston amplitude $(10 \mathrm{~mm})$, the trends of the predicted efficiency curves seemed worse.

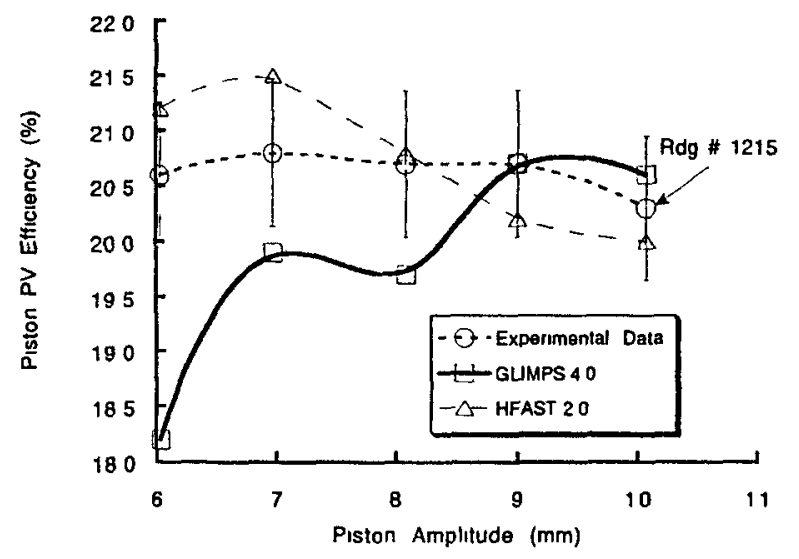

Figure 10 - SPRE Piston PV Efficiency vs Piston Amplitude (Calibrated Predictions)

\section{CONCLUDING REMARKS}

GLIMPS and HFAST loss comparisons disagree in magnitudes of losses. GLIMPS predicts higher gas-to-wall heat transfer in phase with temperature difference primarily due to larger cylinder heat transfer. GLIMPS also predicts higher gas conduction due to its enhanced conductivity model.
The differences in predicted mixing losses can be attributed to the difference in assumptions about spatial variations of temperature. These differences in losses can cause the codes to optimize engine designs differently.

Both codes require engine-specific calibration parameters to bring predictions and experimental data into agreetnent. It would be desirable to obtain one set of calibration parameters for each code that would allow various Stirling engines to be modeled accurately. However, calibration experience suggests that a "best fit" set of calibration parameters is currently not obtainable.

The results documented in this paper indicate several areas where the codes could be improved. The cylinder heat transfer correlations for both codes should be re-evaluated. Work is currently underway to experimentally measure cylinder heat transfer in Stirling machine cylinders. Empirical correlations should be incorporated in both GLIMPS and HFAST when they become available.

GLIMPS could be further improved in two additional areas. First, the connecting-ducts adjacent to the expansion and compression-spaces should be modeled. The uncalibrated GLIMPS predictions for the SPRE would have been improved if a connecting-duct model existed. The SPRE has an unusually large connecting-duct between the cooler and compression-space. The surface area and volume of this connecting-duct had to be lumped with the compression-space in the SPRE model. Secondly, the parasitic losses should be an integral part of the GLIMPS thermodynamic simulation. These losses influence the predicted engine pressure waves.

Current plans are to continue the validation of GLIMPS and HFAST for the RE-1000 with various working fluids. Predictions will be generated for a kinematic Stirling engine and compared with experimental data. Results of this work will be described in a future NASA technical memorandum.

\section{REFERENCES}

1. J.G. Schreiber, S.M. Geng, and G.V. Lorenz, "RE-1000 Free-Piston Stirling Engine Sensitivity Test Results," NASA TM-88846, 1986.

2. J.E. Cairelli, "SPRE I Free-Piston Stirling Engine Testing at NASA Lewis Research Center," NASA TM-100241, 1987.

3. J. Corey, "Standards and Nomenclature for Reporting of Stirling Engine Performance," 24th IECEC, 1989, Vol. 5, pp. 2325-2329.

4. D. Gedeon, "A Globally-Implicit Stirling Cycle Simulation," 21st IECEC, 1986, Vol. 1, pp. 550-554.

5. D. Gedeon, "GLIMPS version 4.0 User's Manual," Gedeon Associates, 16922 South Canaan Road, A hars OH 45701, 1992, (in press).

6. S.C. Huang, "HFAST: A Harmonic Analysis Program for Stirling Cycles," (To be published in: 27th IECEC, (number 92IECEC425), 1992).

7. K.P. Lee, "A Simplistic Model of Cyclic Heat Transfer Phenomena in Closed Spaces," 18th IECEC, 1983, Vol. 2, pp. 720-723. 


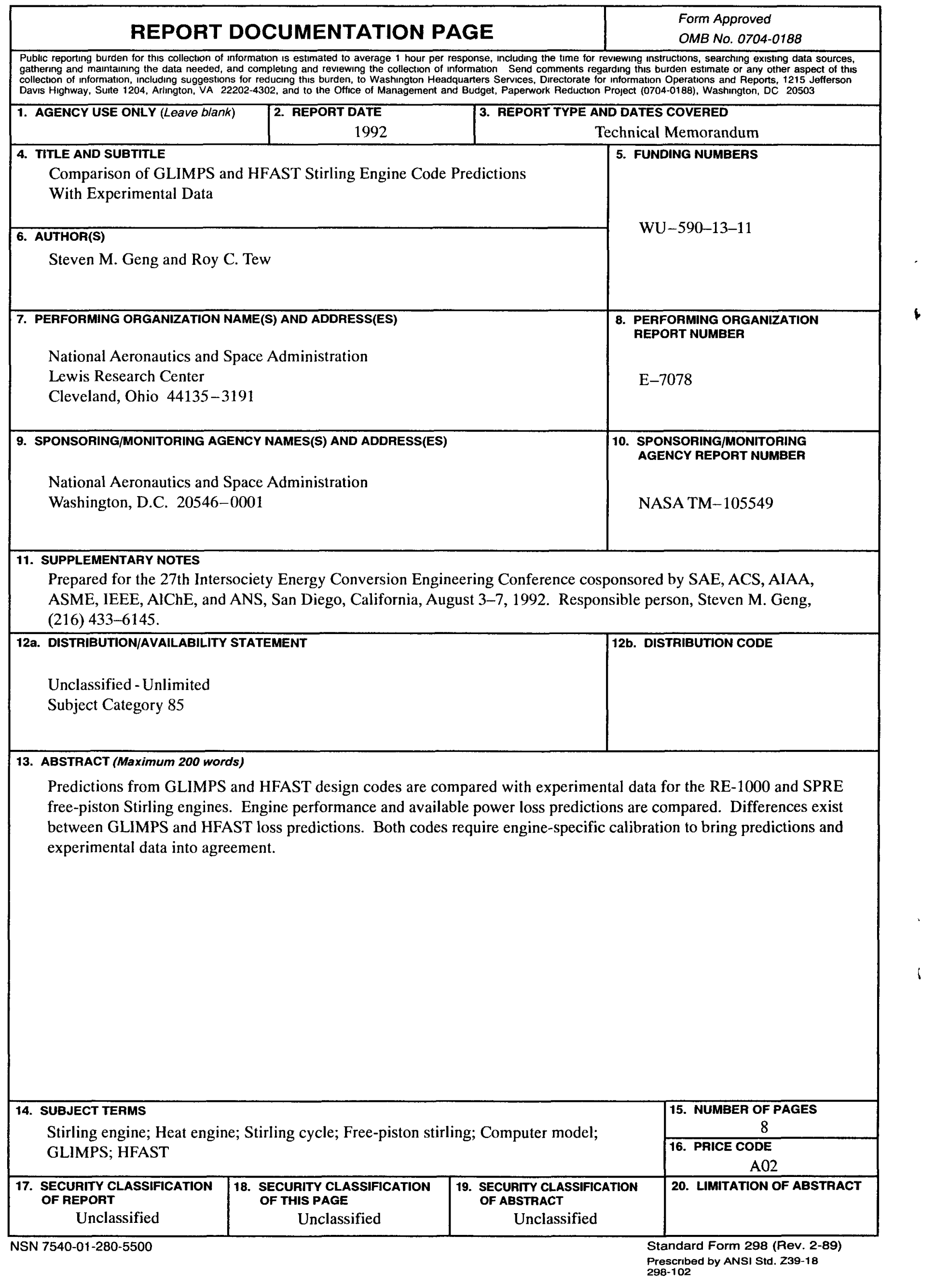


National Aeronautics and

Space Administration

Lewis Research Center

Cleveland, Ohio 44135

Orilicial Businese

Penalty for Private Use $\mathbf{5 3 0 0}$
FOURTH CLASS MAIL

ADDRESS CORRECTION REQUESTED
|||||

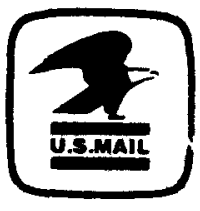

Postage and Fees Pald

National Aeronautics and Space Administration

NASA 451 